\title{
Prime time for DIAMAP: a road map for diabetes research in Europe
}

\author{
P. A. Halban
}

Received: 31 March 2010 / Accepted: 1 April 2010 /Published online: 8 May 2010

(C) Springer-Verlag 2010

Keywords Diabetes research $\cdot$ EUROPE $\cdot$ Research funding $\cdot$ Science policy

\section{European diabetes research: the need for strategic planning}

As already discussed in this journal [1] and elsewhere [2], there is a critical need for more funds for diabetes research in Europe. But for any such investment to pay dividends, there must be a strategic plan for the sustainable development of diabetes research in Europe, with better coordination of such research and more rational (science-based) use of funds, for the benefit of individuals with diabetes. The established approach to research we have today in Europe, with largely random and uncoordinated investment, stifles European research competitiveness. The new European Commissioner for Research and Innovation recognises the problem [3].

To succeed without causing collateral damage, a strategic research plan must not divert funds from pure academic research, which must continue to drive great discoveries as it has throughout history. Provided that investment in research is increased - as is the declared intent of the European Commis-

P. A. Halban

EURADIA (Alliance for European Diabetes Research) and DIAMAP (FP7 project number HEALTH 200701), Düsseldorf, Germany

\section{P. A. Halban $(\bowtie)$}

University Medical Centre, University of Geneva,

1 rue Michel-Servet,

1211 Geneva 4, Switzerland

e-mail: philippe.halban@unige.ch sion and many national governments as part of the Europe 2020 strategy [4] (and which we hope is not doomed to failure like the preceding 10 year Lisbon Strategy) - a strategic research plan and pure academic research are complementary, rather than mutually exclusive, approaches to research funding.

\section{DIAMAP: a road map for diabetes research in Europe}

Recognising the magnitude of the diabetes problem and the specific research challenges and opportunities it presents to Europe, the Health Directorate of the European Commission Directorate General for Research issued a call for projects in the 7th Framework Programme (FP7) that would develop a road map for diabetes research. DIAMAP, the project submitted by EURADIA, the Alliance for European Diabetes Research (www.euradia.org), was accepted for funding [1].

The DIAMAP road map project is now complete. The report, road maps and databases are publicly accessible at www.diamap.eu.

What is DIAMAP? There are two components to the project. The road maps are intended to guide future investment in diabetes research by the European Commission and any other organisation or company interested in this strategic plan. The maps cover research areas considered by a group of leading experts to offer the greatest scientific interest and potential for advancing the field, ultimately for benefit to the patient. This new strategy for European diabetes research is rational, science-driven and takes into consideration the unique expertise and opportunities in Europe. 
The databases provide a snapshot of research that is ongoing in the European region today as well as the amount of money devoted to diabetes research in Europe and the major sources of such funding.

The road maps The road maps cover diabetes research in the very broadest sense, from molecular studies to clinical science and healthcare delivery. The DIAMAP teams were multidisciplinary, with experts from all research communities. There is an emphasis on the need to coordinate diabetes research in Europe, including an ambitious proposal to create a central European resource to facilitate clinical research.

The groups (see www.diamap.eu for a list of experts) developed their road maps using a common strategy. Major advances in each field served as entry points for the research tracks with overarching goals for future research as the endpoints; interim research milestones chart progress along each track with roadblocks identified that prevent progress (Fig. 1). Goals or specific milestones that were considered particularly important for advancement in the field, with readily available European know-how, are flagged as priorities. The Horizontal Issues group worked in parallel, addressing crosscutting and generic issues, such as ethics and training.

The databases The research database is a unique, fully interactive resource providing detailed information on who is doing what and where in diabetes research in Europe. It also provides information on specific resources or techniques used by these investigators. The funding database contains information obtained from national and international public and charitable funding agencies and provides unique insight into the landscape of diabetes research funding in Europe, with data for most European countries, including best estimates of the total annual investment in diabetes research in Europe. Confidentiality was strictly respected in developing the public databases.
Who should benefit from DIAMAP? What are its possible weaknesses? All stakeholders in Europe interested in any aspect of diabetes research should benefit from DIAMAP: patients, researchers from all disciplines and subspecialities related to the disease, payers and science policy-makers. With the (admittedly very ambitious) proviso that major funding agencies adopt the road map strategy and manage to coordinate their funding, ideally through a central resource such as EURADIA, DIAMAP could have a huge and very positive impact on diabetes research in Europe. It would allow European diabetes research to be better coordinated and focused than ever before, making the whole enterprise more rational and cost-effective, ensuring greater benefit to individuals with diabetes.

That being said, some may not appreciate DIAMAP or these potential benefits right away: they will cry foul! Researchers are notoriously protective of their academic independence. Any top-down approach that restricts funding to specific areas of research is contested and resented. That is exactly why it is so important to guarantee that funding for investigator-initiated research is not impacted by a strategic plan such as DIAMAP. Equally, funding agencies, especially those with a very focused mission, consider themselves best able to identify research most likely to benefit their own constituency. DIAMAP will allow them to do so by selecting milestones from the road maps. The final choice will still be theirs but in the knowledge that it is supported by an outstanding group of outside experts.

There are surely some weaknesses. Like any academic exercise, the value of DIAMAP depends on the expertise, selflessness and vision of those contributing to the project. While their remit was to be as broad-ranging and objective as possible, no project such as this can be all-embracing. The experts spent a lot of time and effort creating the maps, always keeping in mind potential benefit for the patient while taking into consideration feasibility and specific opportunities for European science. Are there holes in the

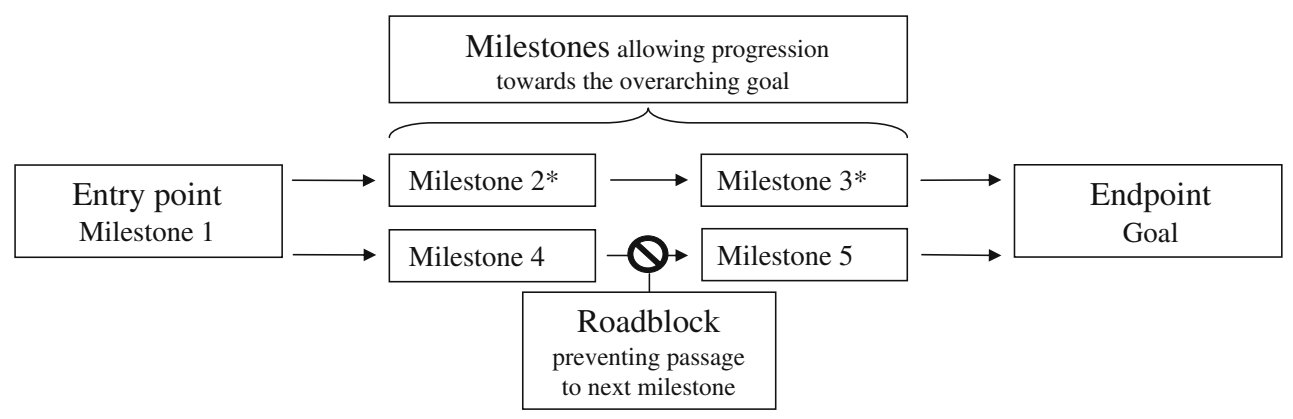

Fig. 1 Example of a road map. In this example, a single entry point (Milestone 1) leads to two parallel tracks (Milestones 2, 3 and 4, 5) that each advance towards a common endpoint or overarching goal. Actual tracks from each road map feature alternative (simpler or more complex) layouts of the milestones, with the purpose of moving research from the entry point(s) to a common endpoint. Only the most specific and critical roadblocks are indicated in the tracks. *Milestones/tracks that are considered to be especially important to the field, as well as appropriate for immediate investment with the necessary expertise and technology already in place, are indicated as a priority 
road maps? There surely are. Is it possible to second-guess this group of experts and come up with another set of maps, with different tracks and endpoints? Of course! But this is not an absolute science. DIAMAP was never intended to provide a definitive diabetes research road map; there can be no such thing, but this should not make the strategy less useful. This must be a continuously evolving story, with feedback from all communities allowing improvement and refinement in an iterative process.

The challenge for the databases was to capture relevant information from all European senior/independent investigators and funding agencies. The research database does provide a usefully representative snapshot in time of European diabetes research, even if it certainly does not feature every independent investigator working in the field in Europe (not from lack of trying). The funding database was a particular challenge. Although the information is both extensive and useful thanks to the extraordinarily hard work of the DIAMAP staff, it is not complete, especially at the level of national government funding. Perhaps such a survey of research funding can only succeed if undertaken by a central authority: civil servants would be encouraged to seek the relevant information if the request came from on top, through their ministry in response to the European Commission. In any case, data acquisition and analysis must continue for both databases to make them even more informative and to ensure that they remain up to date.

Ultimately, the success of this road map strategy will depend not only on the quality of the maps but also on how they are used. Aside from the obvious and primary goal of guiding the choice of research areas for future investment, in the longer term such a strategy cannot succeed unless there is constant monitoring of progress and some way to ensure that the European diabetes research effort is coordinated. This could best be achieved by the creation of a central entity, a virtual European Diabetes Institute. Such an institute would not perform research itself and neither would it provide funds. It would ensure that European diabetes was coordinated, and would monitor progress in the various DIAMAP research tracks and refine them as mentioned above. This would allow Europe to capitalise fully on the initial investment in this unique endeavour.

Acknowledgements DIAMAP was supported by the European Commission Seventh Framework Programme, grant number FP7 HEALTH 200701.

Duality of interest The author declares that there is no duality of interest associated with this manuscript.

\section{References}

1. Halban PA, Smith U (2008) Order! Order! Order in the House! DIAMAP: a road map for European diabetes research. Diabetologia 51:1765-1767

2. Halban PA, Ferrannini E, Nerup J (2006) Diabetes research investment in the European Union. Nat Med 12:70-72

3. Laursen L (2010) New commissioner spells new direction for EU research funding. Nat Med 16:247

4. European Commission (2010) Europe 2020: a European strategy for smart, sustainable and inclusive growth. Available from http:// ec.europa.eu/commission_2010-2014/president/news/documents/ pdf/20100303_1_en.pdf, accessed 9 April 2010 